\title{
Mar de longo: um Porto para a literatura brasileira
}

Francisco Topa

Professor da Universidade do Porto / Centro de Investigação Transdisciplinar «Cultura, Espaço e Memória - CITCEM

Refletir sobre trinta anos de investigação e ensino da literatura brasileira numa universidade portuguesa obriga a uma reflexão que, sendo sempre pessoal, impõe também que se considere um contexto que foi mudando ao longo do tempo, acompanhando os altos e baixos do Brasil, a flutuação da sua imagem no exterior, a oscilação das relações lusobrasileiras e dos respetivos momentos migratórios.

Quando, em 1990, comecei a trabalhar nesta área, já o ensino da literatura brasileira estava bem implantado na Universidade do Porto. Iniciada em 1970 - faz agora meio século pelo Prof. Arnaldo Saraiva (figura bem conhecida no Brasil pelos seus estudos sobre o modernismo e variadíssimas outras matérias e sócio correspondente da Academia Brasileira de Letra), a área fora-se impondo internamente, ganhando prestígio e espaço curricular, e externamente, tanto a nível nacional como no plano internacional. De algum modo beneficiava ainda da "explosão" do número de estudantes universitários proporcionada pela Revolução dos Cravos, do prestígio e da popularidade de alguns escritores brasileiros hostilizados em Portugal durante o Estado Novo e da curiosidade perante um país que chegava à maioria dos portugueses através das telenovelas. O Brasil era nessa altura um país distante, de onde não era fácil obter livros nem informações, o que dificultava sobremaneira a preparação de aulas e a realização de pesquisas, tanto mais que - pelo menos na área das humanidades - os centros universitários de investigação e a agência nacional de fomento estavam ainda a começar ou passavam por uma reestruturação profunda.

Era esta uma época em que a literatura brasileira, não sendo obviamente desconhecida em Portugal, não tinha ainda aqui uma presença transversal: poucas editoras publicavam regularmente livros brasileiros; à exceção de alguns clássicos mais antigos e dos romancistas

Gláuks: Revista de Letras e Artes - jul/dez 2020 - v. 20, n. 2 
de 30, o panorama editorial de incidência brasileira era pobre; os autores brasileiros quase não tinham presença nos programas e nos manuais de língua portuguesa; com poucas exceções, a imprensa (mesmo a especializada) acompanhava de longe o que ia saindo no Brasil. Aos poucos, porém, o cenário foi mudando, quero crer que devido sobretudo a dois fatores: por um lado, à melhoria progressiva da imagem externa do Brasil, particularmente durante as presidências de Fernando Henrique Cardoso e de Lula da Silva; por outro, devido ao impacto que gerações sucessivas de novos professores de língua portuguesa dos ensinos básico e secundário, formados com programas que incluíam a literatura brasileira, começaram a ter junto dos jovens portugueses e da sociedade em geral.

Como acontece em todos os centros de estudos brasileiros fora do Brasil, os recursos antes de mais humanos - são sempre muito limitados, obrigando em geral os seus docentes a atuarem como "generalistas", pelo menos ao nível do ensino de $1 .^{\circ}$ ciclo. No caso da Universidade do Porto, pudemos contar, entre 1990 e 2008, com dois professores, o que permitiu que eu me fosse especializando na literatura brasileira do período colonial, sob a orientação do Prof. Arnaldo Saraiva. Embora de início a minha inclinação fosse outra - como acontece quase sempre com os jovens, mais facilmente atraídos para o presente que para o passado -, fui percebendo que fazia todo o sentido o caminho que o Prof. Saraiva me propôs: porque a fase colonial da literatura brasileira está menos estudada; porque há nos arquivos e bibliotecas portuguesas muita documentação por explorar; porque certas questões e textos se compreendem melhor à luz da tradição literária portuguesa (e europeia).

Do ponto de vista do ensino, a maior utilidade desta especialização verificava-se no $2{ }^{\circ}$ ciclo, sobretudo a partir do momento em que passámos a contar com dois seminários de literatura brasileira, um voltado para o período colonial e outro incidindo sobre a literatura do romantismo em diante. Ao nível da graduação, o ensino coloca outro tipo de problemas, certamente comuns a todos as universidades estrangeiras, isto é, não-brasileiras: estando o espaço curricular limitado a uma ou duas disciplinas, não é possível abordar o objeto nem de modo muito extensivo nem com grande profundidade, sobretudo quando, a par da literatura, há que considerar também certos aspetos da cultura brasileira ou da língua (variante, se falamos do estudo a partir de Portugal). No caso da Universidade do Porto, uma das disciplinas costuma ser reservada a uma visão propedêutica e panorâmica da literatura do

Gláuks: Revista de Letras e Artes - jul/dez 2020 - v. 20, n. 2 
Brasil, numa perspetiva diacrónica que tenta incluir os principais momentos e correntes estéticas, destacando autores e textos canónicos. A segunda unidade curricular pode assim ser usada para suprir as lacunas da outra ou para testar um programa de investigação que esteja a ser desenvolvida pelo(s) docente(s) respetivo(s).

No período em que venho trabalhando nesta área, ocorreram também várias transformações importantes com impacto na forma de abordar a literatura brasileira. Por um lado, deu-se a evolução do próprio sistema - ainda que, vista de fora, ela pareça ter sido relativamente pobre. Se é verdade que há muito mais gente a escrever e que alguma dela tem qualidade acima da média, o sistema em si parece não ter mudado: continua a ser dominado pelo eixo Rio-São Paulo, não foi capaz de romper com a linguagem e com a estética dominantes no passado e não está ainda plenamente integrado num diálogo e num palco verdadeiramente internacionais. Isto é tanto mais estranho quanto, ao nível da crítica e do ensaísmo, a evolução parece ter sido feita em sentido contrário, registando um incremento muito grande, sobretudo ao nível da qualidade. O mesmo aconteceu quanto ao intercâmbio académico: professores e investigadores brasileiros passaram a viajar muitos mais e tornaramse parceiros ativos de redes de investigação internacional, num claro benefício para o sistema científico brasileiro mas também para as universidades e centros de investigação estrangeiros que contam com a colaboração desses profissionais.

À primeira vista falta agora, por um lado, um investimento consistente na promoção da literatura brasileira no exterior, o que pode ser feito através da preparação de antologias (como o "Curso breve de literatura brasileira" que Abel Barros Baptista publicou em Portugal) em línguas como o inglês, o espanhol, o francês, o chinês e o árabe. Por outro lado, e esta é uma tarefa bem mais complicada e demorada, é preciso rever o sistema educativo brasileiro, investindo fortemente - e em todos os níveis de ensino, do elementar ao universitário - nas línguas estrangeiras, designadamente o inglês e o espanhol. Machado de Assis, apesar de não ter seguido estudos regulares, pôde conviver com a grande tradição literária ocidental, mas o seu exemplo está longe de estar generalizado entre as novas gerações da literatura brasileira. E esse é um poderoso fator de empobrecimento.

No período de tempo que estamos a considerar ocorreu também uma mudança acentuada no perfil dos estudantes. Se, na década de 90 , os alunos que buscavam os cursos em

Gláuks: Revista de Letras e Artes - jul/dez 2020 - v. 20, n. 2 
que a literatura brasileira é oferecida procuravam maioritariamente formar-se para serem professores de língua portuguesa nos ensinos básico e secundário, hoje temos pelo menos duas tendências contrárias: o estudante casual, que vem apenas experimentar e que muitas vezes abandona o curso; e o aluno comprometido, que gosta de ler e que lê muito para além da bibliografia obrigatória, que escreve bem, que tem uma boa formação cultural de base e que tende a fazer depois uma formação pós-graduada. Entre estas duas tendências, há o discente médio, que pouco sabe do Brasil, da sua cultura e da sua literatura, para quem se trata de um país estranho, esquisito, cuja maior parte da população vive em favelas e assolada por problemas como a violência e a corrupção. Para este último, terá sido útil a introdução, em 2008, da disciplina de Cultura Brasileira, cujo primeiro objetivo é justamente apresentar o Brasil e analisar alguns dos mitos e preconceitos que habitualmente marcam a sua visão no exterior.

Um último aspeto que mudou no panorama estudantil foi a chegada de alunos brasileiros, sensivelmente a partir de 2010. Alguns deles vieram ao abrigo dos PLI (Programas de Licenciaturas Internacionais), outros beneficiaram de planos de mobilidade, outros ainda são filhos de brasileiros que se mudaram para Portugal. A sua chegada à Universidade do Porto tem tido um efeito, do meu ponto de vista, muito positivo: para os professores e para as aulas, dinamiza e enriquece o debate em torno dos textos e do seu contexto; para os alunos portugueses e de outra proveniência (estes geralmente ao abrigo do Programa ERASMUS) representa a oportunidade de um contacto direto com certos aspetos da cultura e da vida brasileiras.

Uma última mudança, em parte relacionada com o ponto anterior, tem que ver com a alteração de paradigmas, nos estudos literários e na sociedade em geral. Se podemos dizer que a conceção de texto literário não se alterou muito nas últimas décadas, apesar dos avanços na teoria literária, a verdade é que mudou muito a maneira como a representação dos negros, das mulheres e de uma série de minorias passou a ser vista e estudada. Acompanhando, e às vezes antecipando, essas tendências, também os nossos programas e a nossa leitura se foram modificando, o que nem sempre é facilmente acompanhado pelos alunos portugueses, muitos deles ainda educados segundo uma visão colonial e imperial, de acordo com a qual o Brasil e os brasileiros são meros filhos de Portugal.

Gláuks: Revista de Letras e Artes - jul/dez 2020 - v. 20, n. 2 
Passando agora à parte da investigação, diria que a opção anteriormente referida pelo período colonial acabaria por me levar, quando preparava uma prova equivalente ao mestrado, a um dos árcades mineiros, Silva Alvarenga, figura multifacetada da última fase do período colonial que se destacou como poeta, professor e intelectual progressista. O tipo de material que fui encontrando acabaria por determinar o caminho que escolhi naquela altura e que continuaria a seguir no futuro: a crítica textual. De facto, percorrendo as bibliotecas e arquivos de Portugal, encontrei uma série de manuscritos com textos inéditos, assim como diversas edições que eram desconhecidas dos especialistas e que nunca tinham sido usadas para o estabelecimento do texto da obra do autor de Glaura, o que me levou (Topa, 1994 e 1998c) a propor as bases para uma edição crítica completa da obra desse autor. Entre o material inédito que encontrei havia um texto particularmente interessante: Reflexoens Críticas sobre a Ode do bacharel Domingos Monteiro. Por Manuel Inácio da Silva Alvarenga, estudante na nova Universidade de Coimbra. Como o sugere o título, trata-se de uma peça em que Silva Alvarenga analisa (e destrói) um poema de um seu contemporâneo português que havia feito uma crítica (infelizmente perdida) ao vate de Vila Rica. Com muita ironia e humor, o jovem Alvarenga revela-se um crítico implacável, dando-nos um dos poucos exemplos, na literatura brasileira deste período, do exercício desta atividade essencial à instituição literária e mostrando-nos como a boa (mesmo se 'maldosa') crítica não pode existir sem uma sólida preparação teórica. 


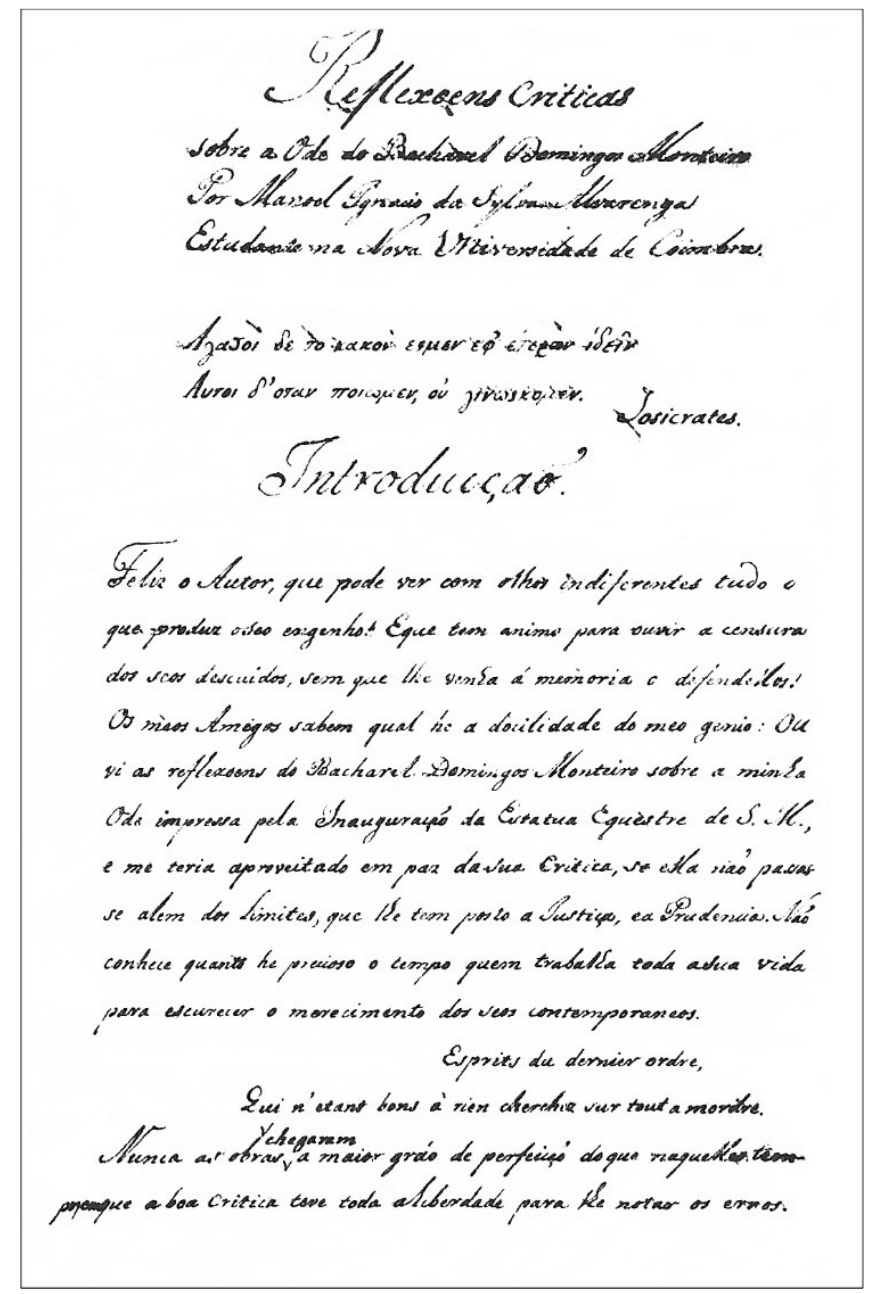

Fólio inicial do Ms. CIX/1-10 da Biblioteca Pública de Évora com o texto de Silva Alvarenga

Outro texto interessante do jovem Alvarenga cujo estudo me acompanhou durante bastante tempo foi uma epístola, em versos alexandrinos, que ele dirigiu ao seu companheiro, e de algum modo mentor, Basílio da Gama: publicada em 1772, em Coimbra, essa carta (começada pelo verso "Génio fecundo e raro, que com polidos versos") dedica uma parte importante à crítica (favorável) de $O$ Uraguai, dado ao prelo três anos antes. Mas o objetivo de Alvarenga é mais largo: em sintonia com os teóricos da época, o futuro colaborador de $O$ Patriota propõe um conjunto de orientações doutrinárias, acompanhando essa exposição de uma crítica contundente tanto à estética barroca e a alguns dos seus representantes tardios como aos lugares-comuns do arcadismo. A última etapa do estudo desse texto aconteceu em

Gláuks: Revista de Letras e Artes - jul/dez 2020 - v. 20, n. 2 
2014, em Assis, onde lecionei um curso sobre crítica textual cujo trabalho de avaliação final consistiu justamente na edição crítica e no estudo desse poema (Topa, 2014b).

\section{A TERMINDO \\ S I P I L I O \\ A R C A D R R MANO \\ POR \\ ALCINDO PALMIRENO}

ARCADE ULTRAMARINO.

EP IS T OLA

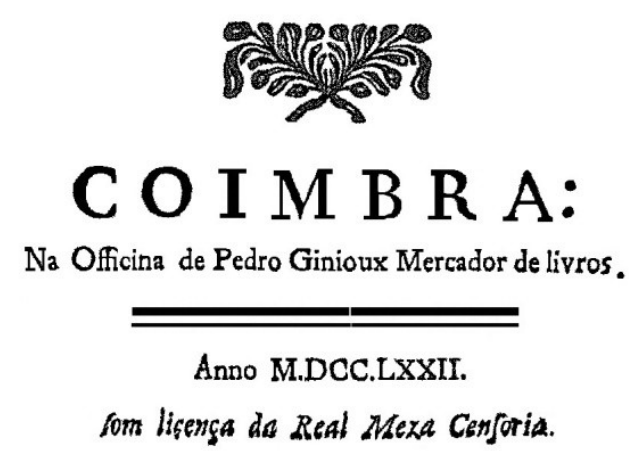

Folha de rosto da edição de 1772 da epístola de Alvarenga

A pesquisa sobre Silva Alvarenga permitiu-me encontrar uma série de outros inéditos ou de versões novas de vários outros poetas brasileiros do período colonial, que fui estudando e publicando nos anos seguintes: os mineiros Basílio da Gama (1998a, 200a, 2000b, 2003a), Alvarenga Peixoto (1998b e 1998d) e Frei José de Santa Rita Durão (2002b), mas também outros poetas de setecentos (ainda) menos conhecidos, como Manuel de Macedo Pereira de Vasconcelos (1726-post 1788), natural do Sacramento (Topa, 2004); Francisco José de Sales (1735?-1800/1801), nascido no Serro do Frio, Minas Gerais (Topa, 2001a); João Pereira da Silva (1743-1818), originário do Rio de Janeiro (Topa, 2001b).

Gláuks: Revista de Letras e Artes - jul/dez 2020 - v. 20, n. 2 
$\mathrm{Na}$ mesma linha de trabalho, começara entretanto a preparar a minha tese de doutoramento, sobre Gregório de Matos. Terminada em 1999 (Topa, 1999), tinha como objetivo lançar as bases e dar o primeiro passo para a edição crítica da obra do Boca do Inferno, o que implicava inventariar a mole imensa dos testemunhos (maioritariamente manuscritos) que a transmitiam e avançar com um modelo de edição aplicado a uma parte dela - os sonetos. Uma vez mais, a peregrinatio por tantas bibliotecas e arquivos - de Portugal, do Brasil e de outros países - permitiu-me recolher material que alimentou depois edições de outros poetas brasileiros da época, como Eusébio de Matos (1629-1692), natural de Salvador, como o seu irmão Gregório (Topa, 2011b); João Mendes da Silva (1659-1736), oriundo do Rio de Janeiro, pai do malogrado António José da Silva, conhecido como O Judeu (Topa, 2002a, 2014a e 2019b); ou Gonçalo Soares da Franca (1678-post 1724), nascido em Salvador e membro da Academia Brasílica dos Esquecidos (Topa, 2012b). Estou agora a preparar o estudo e edição de outro poeta barroco inédito, o luso-brasileiro Cláudio Grugel do Amaral (cf. Topa, 2000).

Que interesse tem este tipo de trabalho, condenado quase sempre a permanecer n' $a$ mais discreta sombra (para retomar um verso de Miguel Torga)? Por um lado, ajuda-nos a saber um pouco mais do passado e do processo de formação de uma entidade a que hoje chamamos Brasil, permitindo-nos identificar figuras (maiores ou menores pouco importa) da cultura brasileira e avaliar o seu trabalho; por outro lado, mostra-nos o muito que ainda não sabemos sobre o Brasil colonial, tanto ao nível da chamada alta cultura quanto no que diz respeito ao quotidiano mais velado. Sirva de exemplo um pequeno estudo que fiz sobre os poemas de Gregório de Matos dominados pelo tópico da menstruação (Topa, 2019a). Trata-se de um tema tabu, pouco abordado fora da bibliografia médica ou sanitária, e que, tanto quanto pude apurar, quase não tem tradição literária, pelo menos fora da contemporaneidade. Apesar disso, Gregório tem um conjunto de quatro poemas sobre o assunto, ensaiando uma série de interessantes e às vezes inesperadas variações imagéticas, num registo em que o fescenino é atenuado pelo humor. Mas o que é mais interessante é que, por trás do investimento retórico, há uma série de indicações sobre as vivências da época, algumas delas inesperadas. É o que acontece numa passagem em que o sujeito, declarando ter atingido o ápice da frustração e do desespero, propõe à amante a quebra do maior tabu que rodeia a menarquia: a prática do sexo

Gláuks: Revista de Letras e Artes - jul/dez 2020 - v. 20, n. 2 
durante o período menstrual. Curiosa é também a referência ao mangue enquanto espaço capaz de garantir alguma privacidade ou às formas de higiene masculina após a consumação do ato.

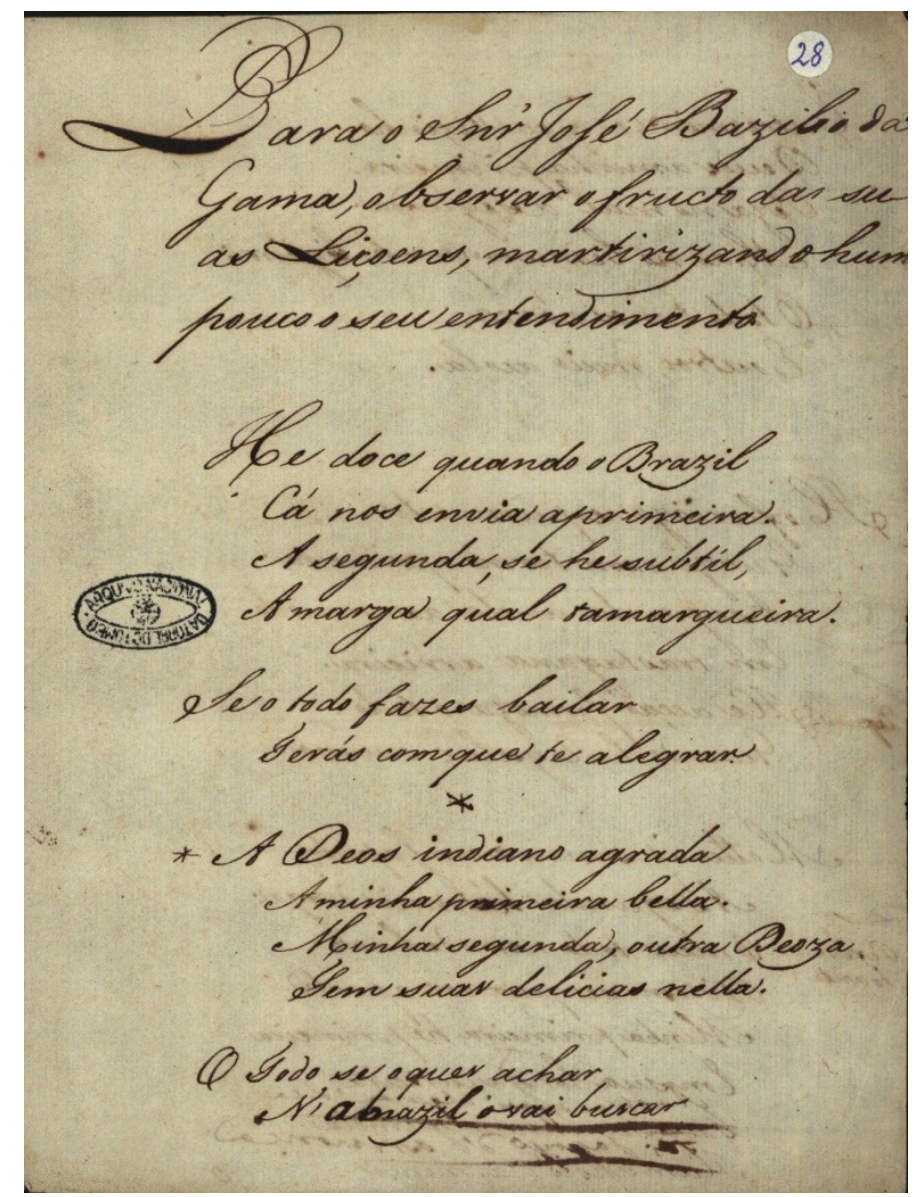

Fólio inicial do n. ${ }^{\circ} 28$ dos Avulsos 3 da coleção Papéis do Brasil (Arquivo Nacional da Torre do Tombo, Lisboa)

Esta dimensão do texto literário como documento que contém motivos de interesse para diversos domínios da história é particularmente visível em textos do período colonial. É o que tenho tentado mostrar em pequenos trabalhados mais ou menos pontuais, sobre temas tão diversos como o testamento satírico de um governador do Rio de Janeiro (Topa, 2008), a administração de Serro do Frio (Topa, 2003c) ou enigmas da história culinária luso-brasileira (Topa, 2011c e 2018).

Nada disto porém tem grande significado se considerarmos a vastidão da seara que há para trabalhar (e o pequeno número de operários dispostos a colaborar nesta tarefa). 
Importante é não perdermos de vista que a literatura brasileira e as suas relações com Portugal são o mar de longo de que falava Caminha na sua carta a D. Manuel - e que todos somos poucos para o enfrentar. No Porto, na senda do exemplo - a todos os títulos pioneiro - de Arnaldo Saraiva, a literatura do Brasil continuará a ter um porto seguro, protegido pel' a mais discreta sombra.

\section{Referências Bibliográficas}

TOPA, Francisco (1994). Silva Alvarenga: contributos para a elaboração de uma edição crítica das suas obras. Porto: FLUP. (Policopiado)

(1998a). Duas quadras inéditas de José Basílio da Gama. Revista da Faculdade de Letras: línguas e literaturas. Porto. II: XV, pp. 453-454

(1998b). Novas versões para sete poemas de Alvarenga Peixoto: propostas de emenda à edição de Rodrigues Lapa. Revista da Faculdade de Letras: línguas e literaturas. Porto. II: XV, pp. 445-451

(1998c). Para uma edição crítica da obra do árcade brasileiro Silva Alvarenga: inventário sistemático dos seus textos e publicação de novas versões, dispersos e inéditos. Porto: Edição do Autor.

(1998d). Um soneto inédito de Alvarenga Peixoto. Revista da Faculdade de Letras: línguas e literaturas. Porto. II: XV, pp. 439-443

(1999). Edição crítica da obra poética de Gregório de Matos - 2 volumes em quatro tomos. Porto: Edição do Autor

(2000a). A edição crítica dos sonetos de Basílio da Gama: perspectivas. Revista da Faculdade de Letras: línguas e literaturas. Porto. II: XVII, pp. 277-285

(2000b). Basílio da Gama: a obra por vir: 7 inéditos e uma nova versão. In SARAIVA, Arnaldo, org. - Literatura brasileira em questão: actas do II Congresso Português de Literatura Brasileira (8 a 10 de Maio de 1997). Porto: Centro de Estudos Brasileiros da Faculdade de Letras do Porto, pp. 503-517

Edição do Autor

(2001a). Poesia dispersa e inédita do setecentista brasileiro Francisco José de Sales. Porto:

Gláuks: Revista de Letras e Artes - jul/dez, 2020 - v. 20, n. 2 
(2001b). Uma ode e cinco sonetos inéditos do brasileiro João Pereira da Silva. Revista da Faculdade de Letras: linguas e literaturas. Porto. II: XVIII, pp. 277-286

(2002a). Poesia inédita do brasileiro João Mendes da Silva. Revista da Faculdade de Letras: línguas e literaturas. Porto. II: XIX, pp. 301-327

(2002b). Uma égloga inédita de Santa Rita Durão. Terceira margem: revista do Centro de Estudos Brasileiros (Adolfo Casais Monteiro). Porto. 3, pp. 15-18

(2003a). «A declamação lírica» de Basílio da Gama: um inédito recuperado. Revista da Faculdade de Letras: línguas e literaturas. Porto. II: XX, t. I, pp. 187-221

(2003b). O alexandrino e o 'além dos mares': a propósito de uma epístola a Basílio da Gama. Terceira margem: revista do Centro de Estudos Brasileiros (Adolfo Casais Monteiro). Porto. 4, pp. 21-32

(2003c). Poesia (pouco) diamantina: doze sonetos inéditos alusivos à administração mineira de Serro do Frio. Revista da Faculdade de Letras: línguas e literaturas. Porto. II: XX, t. I, pp. 223-233

(2004). Seis poemas inéditos do brasileiro Manuel de Macedo Pereira de Vasconcelos. Revista da Faculdade de Letras: línguas e literaturas. Porto. II: XXI, pp. 303-313

(2005). Um Tomás contumaz: a prisão de Pinto Brandão na Baía e um inédito de Gregório de Matos sobre o tema. Revista da Faculdade de Letras: línguas e literaturas. Porto. II: XXII, pp. 591608. (Com Andreia Amaral)

(2008). A sátira depois da morte: um testamento em verso do Governador Luís Baía Monteiro, o 'Onça'. Navegações: revista de cultura e literaturas de língua portuguesa. Porto Alegre / Lisboa. I: 1 , pp. 67-70

(2011a). Gregório de Matos: poeta polémico (com um exemplo inédito). In CHAVES, Vania Pinheiro, org. - Literatura brasileira sem fronteiras. Lisboa: CLEPUL, pp. 95-108

(2011b). «efímera de um só dia»: dois poemas inéditos de Eusébio de Matos. Patrimônio e memória: revista eletrônica do CEDAP. Assis. 7: 1 (jun.), pp. 207-227

(2011c). Um inventor poeta: a geleia de Alexandre Inácio Silveira oferecida à Princesa do Brasil. Navegações: revista de cultura e literaturas de lingua portuguesa. Porto Alegre / Lisboa. IV: 1, pp. 110-113

(2012a). 'Da colher à boca': os dois sonetos de Caldas Barbosa revelados por Tinhorão. Anthesis: revista de letras e educação da Amazônia Sul-Ocidental. U. Federal do Acre. 1: 2, pp. 141148

(2012b). Um G(onç)alo Renascido: poesia inédita do brasílico Gonçalo Soares da Franca. Introdução e edição de Francisco Topa. Porto: Sombra pela cintura

(2013). 'Se da dor são as lágrimas abono': um desconhecido soneto de Gregório de Matos dos tempos de Coimbra. Navegações: revista de cultura e literaturas de língua portuguesa. Porto Alegre /

Gláuks: Revista de Letras e Artes - jul/dez 2020 - v. 20, n. 2 
Lisboa. VI: 1, pp. 122-123

(2014a). «Qual é a cousa no mundo mais amada?» Responde o Doutor João Mendes da Silva, pai de o "Judeu”. Introdução e edição por Francisco Topa. Porto: Sombra pela cintura

(2014b). «Da simples natureza guardemos sempre as leis»: a epístola de Silva Alvarenga a Basílio da Gama. Miscelânea: revista de literatura e vida social do Programa de Pós-Graduação em Letras da UNESP / Assis. 15 (jan.-jun.), pp. 223-250. (Com Aline Cataneli, Alzira Martins, Áureo Camargo, Gláucia Vieira, Helton Marques, Luiz Eduardo Amaro, Luiz Fernando Garcia, Mariane Severino e Natália Nascimento)

(2018). Um desafio em forma de enigma proposto a Basílio da Gama. Texto Poético: revista do GT Teoria do Texto Poético (ANPOLL). 24, pp. 28-38

(2019a). L'hôte impertinent : le thème de la menstruation dans la poésie de Gregório de Matos. E-Letras com vida: revista de humanidades e artes. 3, pp. 136-143

(2019b). The religious poetry of the Portuguese-Brazilian new Christian João Mendes da Silva. eHumanista: Journal of Iberian Studies. Santa Barbara, California. 41, pp. 171-182

(2020). Cláudio Grugel do Amaral e Frei Bernardo de Brito: sentidos da paródia. O Eixo e a Roda: Revista de Literatura Brasileira. Faculdade de Letras da Universidade Federal de Minas Gerais. 29, 3: Relações Brasil / Portugal. [Em preparação] 